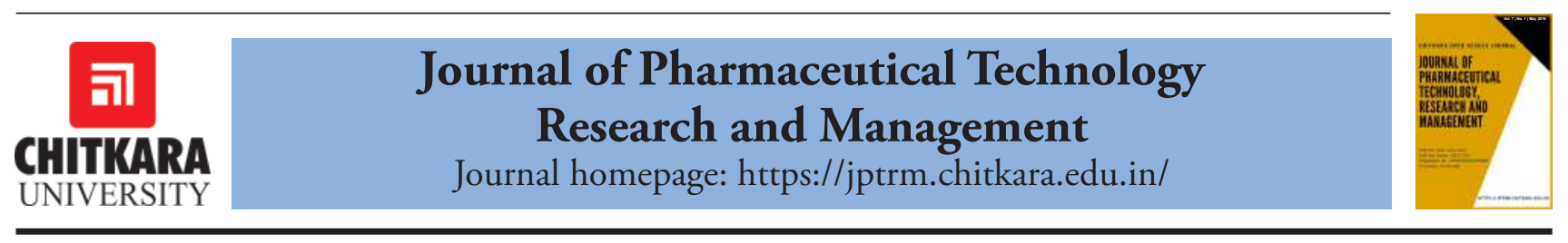

\title{
The Effect of Modification Methods on the Properties of Lentinus Tuber Regium Powders
}

Kenneth C. Ugoeze ${ }^{1}$, Nkemakolam Nwachukwu ${ }^{1 *}$ and Precious C. Anyino ${ }^{1}$

${ }^{1}$ Department of Pharmaceutics and Pharmaceutical Technology, Faculty of Pharmaceutical Sciences, University of Port Harcourt, Port Harcourt, 500004, Rivers State, Nigeria

*Email:nkemakolam.nwachukwu@uniport.edu.ng

\section{ARTICLE INFORMATION}

Received: Nov. 22, 2018

Revised: January 29, 2019

Accepted: Feb. 28, 2019

Published online: May 10, 2019

Keywords:

Modification; Properties; Lentinus Tuber Regium; Powders

\section{ABSTRACT}

The current work considered the influence of methods of modification on the physical characteristics of Lentinus Tuber Regium (LTR) powders. The sclerotia of the LTR was pulverized to $250.0 \mu \mathrm{m}$ and coded as native Lentinus Tuber Regium (NLTR-A). A $500.0 \mathrm{~g}$ of NLTR-A was submerged in $3.5 \% \mathrm{w} / \mathrm{v}$ sodium hypochlorite and stirred continuously for $30.0 \mathrm{~min}$. The resultant slurry was washed severally with purified water until it was neutral to litmus. The mass was dried in an oven at $60.0{ }^{\circ} \mathrm{C}$ for $2.0 \mathrm{~h}$, pulverized $(250.0 \mu \mathrm{m})$ and was noted as the modified Lentinus Tuber Regium powder (MLTR-B). Another $500.0 \mathrm{~g}$ of NLTR-A was extracted with $70.0 \% \mathrm{v} / \mathrm{v}$ ethanol in a Soxhlet extractor. The resultant powder was dried at $60.0 \mathrm{o} \mathrm{C}$ for $2.0 \mathrm{~h}$, micronized $(250.0 \mu \mathrm{m})$ and coded as the modified Lentinus Tuber Regium powder (MLTR-C). Additional $500.0 \mathrm{~g}$ of NLTR-A was submerged in $600.0 \mathrm{~mL}$ of $0.5 \mathrm{~N}$ sodium hydroxide in a $1.0 \mathrm{~L}$ beaker and shaken constantly for $30.0 \mathrm{~min}$. The subsequent material was splashed with purified water until the material was neutral to litmus. The mass was freed from water and introduced into $200.0 \mathrm{~mL}$ of $0.5 \mathrm{~N}$ hydrochloric acid. It was agitated for $30.0 \mathrm{~min}$ in a water bath at $100.0^{\circ} \mathrm{C}$. It was flooded in purified water until it was neutral to litmus. The product was dried to constant weight at $60.0^{\circ} \mathrm{C}$ and pulverized $(250.0$ $\mu \mathrm{m})$. The product was coded as the modified Lentinus Tuber Regium powder (MLTR-D). Generally, NLTR-A, MLTR-B, MLTR-C and MLTR-D were investigated for their organoleptic, solubility, $\mathrm{pH}$, moisture studies, scanning electron microscopy (SEM), x-ray diffractometry (XRD), flow parameters and densities. The results showed that both the native and the modified powders were insoluble in water and most organic solvents. The $\mathrm{pH}$ of the derived powders was consistently higher. SEM and XRD revealed morphological differences in each of the derived powders, though, all the powders were non-crystalline. The respective modification methods brought about an improvement in the hydrophilic and flow properties of the modified powders when compared to the native form of LTR. excipients in terms of improved performance/functionality and the need to simplify the development of innovative drug transport set-ups [7]. Some of the current drug products and new technologies for drug manufacture, especially tablets where direct compression methods are applied require a model filler-binder that could be used as an alternative for two or more excipients. It also requires to meet up with the high-speed rate of modern tableting machines which demand excipients to retain good compressibility and low weight disparity even at little residence period of compression. This would also improve the inadequacies of some prevailing tableting additives such as loss of compressibility of microcrystalline cellulose (MCC) upon wet granulation, high moisture sensitivity and poor die filling due to agglomeration, etc. [21]. Much need for improved excipients has led to the consideration of modifying the powder obtained from Lentinus tuber-regium Fr (Polyporaceae) Syn. Pleurotus tuber regium. It is a species of complex mushroom that is fit for human consumption which 
propagates easily in the bush mainly in the hot climates of the world [1]. It breeds commonly on dead woods during damp seasons of the year subject to the environmental condition. It has become possible to propagate it in the laboratory setting $[17,6]$. Irrespective of the setting of growth, it produces sclerotia that are fundamentally circular measuring up to 30.0 $\mathrm{cm}$ in diameter when fully mature $[26,5]$. Taxonomically, Lentinus tuber regium fits into the Basidiomycete sub-division /phylum and Agariceae family [20]. In Nigeria, it is named 'ero usu'(Igbo), 'katala' (Hausa) and 'obu' (Yoruba). Its dietetic significance has made it an extremely wanted food item having medicinal values and serving for research purposes [15, 2]. In southern Nigeria, its cake is deliciously consumed extensively. It is utilized as a soup thickener either alone or in mixtures with melon seed. It is used medicinally for the management of headache, fever, constipation and cancer of the colon [12, 38]. The sclerotum which is ordinarily seen and picked from decomposing woods has a dark brown outward covering while the inner part is off-white in colour. Findings from collected works indicate that LTR contains potassium, calcium, protein, trace quantities of vitamin E, lipid, alkaloids and tannins [3]. Iwuagwu and Onyekweli (2002) conducted preliminary work on the applicability of LTR powder as a tablet disintegrant. Okoye and Onyekweli (2016) documented the use of the powder derived from the LTR for direct compression of tablets. Several other studies have been documented by other researchers on the LTR in pharmaceutical formulations (36, $35,33,34)$. This research is designed to consider the effect of the approaches of modification on the physico-chemical properties of the LTR powders.

\section{Experimental}

\subsection{Materials}

The following reagents were used as procured: sodium hypochlorite (Multipro, Nigeria), ethanol, $n$-hexane (JHD, China

\subsection{Methods}

\subsubsection{Procurement and Processing of Samples}

The spheres (sclerotia) of Lentinus tuber regium (LTR) were procured from the Mile 3 main market, Port Harcourt, Nigeria. It was identified and allotted a specimen code: OG-ACC-001-UPH-C-057 in the University of Port Harcourt central herbarium. The cleaned sclerotia were cut in bits and pulverized (Binatone, Japan) to 250.0 $\mu \mathrm{m}$ and coded as native Lentinus tuber regium powder (NLTR-A). A $500.0 \mathrm{~g}$ of NLTR-A was submerged in 3.5 $\% \mathrm{w} / \mathrm{v}$ sodium hypochlorite and stirred continuously for $30.0 \mathrm{~min}$. The resultant slurry was washed severally with distilled water until it was neutral to litmus. The mass was dried-up in an oven (New Life, DHG, England) at $60^{\circ} \mathrm{C}$ for $2.0 \mathrm{~h}$ and pulverized $(250.0 \mu \mathrm{m})$. The sample was noted as the modified Lentinus tuber regium powder (MLTR-B). Another $500.0 \mathrm{~g}$ of NLTR-A was extracted with $70.0 \%$ $\mathrm{v} / \mathrm{v}$ ethanol in a Soxhlet extractor. The resultant powder was dried at $60^{\circ} \mathrm{C}$ for $2.0 \mathrm{~h}$. The sample was designated as the modified Lentinus tuber regium powder (MLTR-C). Additional $500.0 \mathrm{~g}$ of NLTR-A was submerged in $600.0 \mathrm{~mL}$ of $0.5 \mathrm{~N}$ sodium hydroxide in a $1.0 \mathrm{~L}$ beaker and agitated constantly for $30.0 \mathrm{~min}$. The subsequent material was flooded with purified water until it was neutral to litmus. The mass was freed from excess water and introduced into $200.0 \mathrm{~mL}$ of $0.5 \mathrm{~N}$ hydrochloric acid. It was shaken for $30.0 \mathrm{~min}$ in a water bath at $100.0^{\circ} \mathrm{C}$ and later flooded with purified water to have it neutral to litmus. It was dried to a constant weight at $60{ }^{\circ} \mathrm{C}$ and pulverized $(250.0 \mu \mathrm{m})$ and coded as the modified Lentinus tuber regium powder (MLTR-D).

\subsubsection{Characterization of the native and the improved Lentinus tuber regium powders}

The Properties of NLTR-A, MLTR-B, MLTR-C and MLTR-D were evaluated as follows after they were examined for colour, texture, odour and taste.

\subsection{3 pH measurement}

The $\mathrm{pH}$ of a $2.0 \% \mathrm{w} / \mathrm{v}$ slurry of each of the powders was evaluated with a $\mathrm{pH}$ meter (Corning, model 10, England).

\subsubsection{Hydration capacity}

Utilizing the technique of [19], the hydration capability of each of the powders was determined. A $1.0 \mathrm{~g}$ quantity was retained in a $15.0 \mathrm{~mL}$ plastic centrifuge tube. A 10.0 $\mathrm{mL}$ volume of water was introduced and later agitated. The set-up was additionally shaken once in a while for the next $2.0 \mathrm{~h}$ period and kept still for $30.0 \mathrm{~min}$. It was centrifuged at 3000.0 revolutions per minute (rpm) for $10.0 \mathrm{~min}$. The supernatant water was decanted and the mass of the wet powder was determined. The procedure was repeated trice. The hydration capacity was calculated using equation 1 as the mass of the damp powder, $x$ against that of the dry powder, $y$.

$$
\text { Hydration capacity }=\frac{x}{y}
$$

\subsubsection{Swelling index}

The swelling index of the samples were determined using a slight modification of the methods established by [9]. A 
$5.0 \mathrm{~g}$ of the powders in turn was retained in a $100.0 \mathrm{~mL}$ graduated measuring cylinder which was tapped, taking note of the tapped volume as $\mathrm{Vx}$. An $85.0 \mathrm{~mL}$ volume of water was used to disperse the powder. The volume was adjusted to $100.0 \mathrm{~mL}$ using water. The set-up was kept still for 24 h. The capacity of the deposit formed, $\mathrm{Vv}$, was evaluated. This process was repeated thrice. The swelling index was calculated from equation 2.

Swelling index $=\frac{V x}{V v}$

\subsubsection{Moisture absorption test}

Saturated solutions of potassium sulphate, potassium chloride, sodium chloride and magnesium nitrate were retained in relative humidity flasks to simulate different relative humidity of $96,84,75$ and $52 \%$ respectively at ambient conditions $\left(29 \pm 1^{\circ} \mathrm{C}\right.$ ) (The Pharmaceutical Codex, 1994). A $1.0 \mathrm{~g}$ mass of each powder in a watch glass was stored in each of the relative humidity for 7 days. Moisture gain was estimated in terms of percentage moisture gain with reference to the initial weight of powder.

\subsubsection{Moisture content}

A tarred empty crucible was weighed and $1.0 \mathrm{~g}$ of the sample was transferred into it and left in the oven at $105^{\circ} \mathrm{C}$. The set up was weighed intermittently until a constant weight was reached [24]. This was performed in triplicates. The proportion of water contained was calculated from Equation 3.

$\left(\frac{w i-w f}{w i}\right) \times 100$

Where, $W_{f}$ is the final weight of powder after drying, and $\mathrm{W}_{\mathrm{i}}$ is the initial weight of powder before drying.

\subsubsection{Scanning Electron Microscopy (SEM)}

The scanning electron microscopies of the samples were evaluated with a scanning electron microscope (Phenom Prox, (PhenomWorld, Eindhoven, Netherlands).

\subsection{8 $X$-ray diffractometry}

The X-ray diffractions of the powders were determined using an X-ray diffractometer (Thermo Scientific, ARL X'TRA, Australia).

\subsubsection{Determination of bulk, tapped and particle densities}

A $20.0 \mathrm{~g}$ quantity of each of the samples was used in the evaluation of bulk and tapped densities by means of a Stampfvolumeter (STAV 2003 JEF, Germany). The procedures were repeated thrice for each powder. The bulk and tapped densities were calculated from equations 4 and 5 respectively.

Bulk density $=\frac{\text { Weight of powder }}{\text { Bulk volume, }, \mathrm{Vo}}$

Tapped density $=\frac{\text { Weight of powder }}{\text { Tapped volume, } \mathrm{Vf}}$

The particle density of each of the powders was established by the solvent displacement technique employing $n$-hexane as non-solvent (Odeku et al, 2005). An unfilled $25.0 \mathrm{ml}$ density bottle was balanced $(W)$. It was occupied with $n$-hexane and reweighed $\left(W_{l}\right)$. The variance among $\mathrm{W}_{1}$ and $\mathrm{W}$ was considered as $W_{2}$. A $0.5 \mathrm{~g}$ amount of the sample was assessed $\left(\mathrm{W}_{3}\right)$ and cautiously conveyed into the density bottle. The superfluous liquid was dabbed and the density bottle was reweighed $\left(W_{4}\right)$. This was conducted three times. Particle density, $\mathrm{P}_{\mathrm{t}}(\mathrm{g} / \mathrm{ml})$ was computed from equation 6 .

$\mathrm{Pt}=\frac{W_{2} \times W_{3}}{V\left(W_{3}-W_{4}+W_{2}+W\right)}$

Where, $v$ is the volume of density bottle, $25.0 \mathrm{ml}$

\subsubsection{Flow properties}

A $50.0 \mathrm{~g}$ amount of each of the powders was used to define the flow rate using the funnel technique [11]. The angle of repose of NLTR-A was estimated by pouring $50.0 \mathrm{~g}$ of each powder into a two open-ended tubular plastic pipe stationed on a level surface of noted diameter. The tubular pipe was gently drawn up so as to constitute a cone of powder on the surface. The altitude of the cone of the powder made was valued. This is an adjusted technique of [18] and the angle of repose got is designated as the static angle of repose. The angle of repose of MLTR-B, MLTR-C and MLTR-D were found as follows. A clean glass funnel was fastened on a retort stand such that a regular perpendicular height of the tip of the funnel was $3.0 \mathrm{~cm}$ from a horizontal flat base with a clean graph sheet of paper. Each powder was, in turn, discharged into the funnel till the powder pile constituted reached the funnel tip and extra discharge of powder from the funnel outlet was clogged [37]. The processes were repeated thrice and the boundaries of the powder mass made in each case were indicated and the diameter of the perimeter of each powder stack was valued with a ruler.

The following calculations were carried out: 
Flow rate $=$ Mass of powder

\section{Time}

Angle of repose, $\theta=\tan -1 \frac{2 h}{d}$

Where, $\theta$ is the angle of repose, $h$ is the height of powder heap, $d$ is the diameter of powder heap.

\subsubsection{Carr's Index (CI)}

Carr's Index [10] was computed by means of bulk and tapped densities data when fitted into the equation:

$$
\text { Carr's Index }=\frac{(\text { Tapped density }- \text { bulk density })}{\text { Tapped density }} \times 100
$$

\subsubsection{Hausner's ratio}

The Hausner's ratio [14] was considered as the ratio of tapped and the bulk densities of the powders.

Hausner ratio $=\frac{\text { Tapped density }}{\text { Bulk density }}$

\subsubsection{Porosity}

The porosity of the respective powders was calculated from the equation:

Porosity $=$ Porosity $=1-\left(\frac{\text { bulk density }}{\text { true density }}\right) \times 100$

\subsubsection{Statistical analysis}

All statistical analysis of data was performed using the IBM SPSS Statistics 20 software at a 95\% confidence interval with the mean difference significant at 0.05 level.

\section{Results and Discussion}

\subsection{Organoleptic, $p H$ and moisture characteristics of the powders}

The results of the properties of the native (NLTR-A) and the modified Lentinus tuber regium powders (MLTR-B, MLTR-C and MLTR-D) are presented in Table 1. Both the native and the modified samples were off-white in colour, tasteless and odourless powders. They were insoluble in water and several organic solvents. All the modified powders showed a significant increase in $\mathrm{pH}$ in comparison with the native sample $(\mathrm{p}<0.05)$. A marked increase in swelling index, moisture content (Figure 1) and hydration capacity were observed in all the modified powders when compared with the NLTR-A $(\mathrm{p}<0.05)$. However, there was an insignificant difference in the results of the hydration capacity of NLTR-A and MLTR-C $(p>0.05)$. The moisture absorption capacity of the powders were in the order MLTR-D >MLTR-C>MLTRB>NLTR-A (Figure 2). This shows that the methods of modification adopted improved the hydrophilic property of the LTR.

Table 1. Properties of the native and the modified Lentinus tuber regium powders

\begin{tabular}{lllll}
\hline \multirow{2}{*}{ Parameter } & Sample & & \\
\cline { 2 - 4 } & NLTR-A & MLTR-B & MLTR-C & MLTR-D \\
\hline Colour & Off white & Off white & Off white & Off white \\
Taste & Tasteless & Tasteless & Tasteless & Tasteless \\
Odour & Odourless & Odourless & Odourless & Odourless \\
$\mathrm{pH}$ & $6.80 \pm 0.01$ & $6.82 \pm 0.01$ & $10.56 \pm 0.01$ & $9.28 \pm 0.01$ \\
Hydration capacity & $4.05 \pm 0.02$ & $4.11 \pm 0.01$ & $4.07 \pm 0.02$ & $4.37 \pm 0.02$ \\
Swelling index & $3.06 \pm 0.01$ & $3.70 \pm 0.01$ & $4.10 \pm 0.02$ & $5.15 \pm 0.02$ \\
Moisture content $(\%)$ & $1.19 \pm 0.01$ & $1.68 \pm 0.02$ & $1.92 \pm 0.03$ & $2.91 \pm 0.02$ \\
Bulk density $(\mathrm{g} / \mathrm{ml})$ & $0.30 \pm 0.01$ & $0.36 \pm 0.02$ & $0.44 \pm 0.01$ & $0.54 \pm 0.02$ \\
Tapped density $(\mathrm{g} / \mathrm{ml})$ & $0.41 \pm 0.01$ & $0.46 \pm 0.02$ & $0.50 \pm 0.12$ & $0.60 \pm 0.01$ \\
Particle density $(\mathrm{g} / \mathrm{ml})$ & $1.18 \pm 0.02$ & $1.61 \pm 0.02$ & $1.71 \pm 0.02$ & $1.85 \pm 0.02$ \\
Flow rate $(\mathrm{g} / \mathrm{s})$ & $0.00 \pm 0.00$ & $10.30 \pm 0.02$ & $11.20 \pm 0.01$ & $12.24 \pm 0.02$ \\
Angle of repose $(\mathrm{deg})$. & $51.46 \pm 0.04$ & $29.72 \pm 0.03$ & $29.24 \pm 0.03$ & $27.41 \pm 0.03$ \\
Carr's index & $29.51 \pm 0.03$ & $12.06 \pm 0.12$ & $11.94 \pm 0.05$ & $9.49 \pm 0.10$ \\
Hausner's ratio & $1.40 \pm 0.02$ & $1.13 \pm 0.01$ & $1.13 \pm 0.01$ & $1.08 \pm 0.01$ \\
Porosity (\%) & $77.83 \pm 0.12$ & $70.25 \pm 0.06$ & $69.72 \pm 0.02$ & $60.48 \pm 0.03$ \\
\hline
\end{tabular}




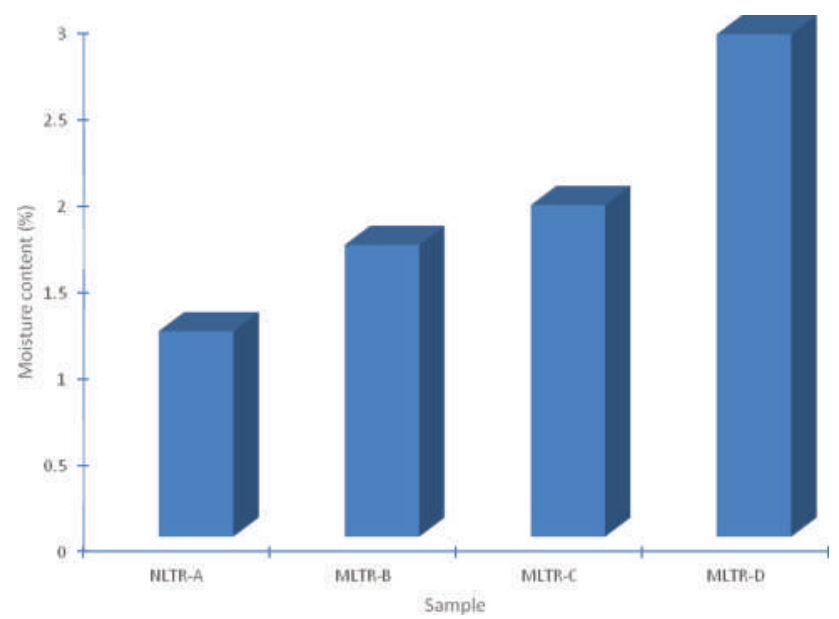

Figure 1. Bar charts showing the moisture content of the native and modified LTR powders.

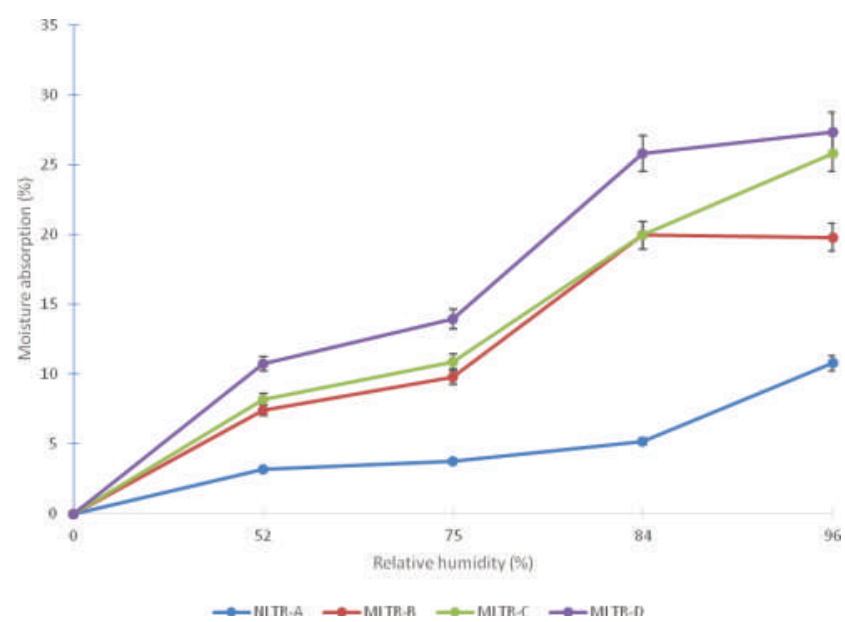

Figure 2. Graph of the moisture absorption capacity of the native and modified LTR powders.

\subsection{Morphological properties}

The morphological studies of the NLTR-A, MLTR-B, MLTR-C and MLTR D respectively using the SEM showed that the respective powders were amorphous and irregularly shaped and contain striations. The scanning electron micrographs of the various samples were different from one another (Figures 3-6). This shows that the methods of modifications used resulted in different morphological outcomes on the native powder of LTR. The results of the $\mathrm{x}$-ray diffractions of the native and the modified samples of the LTR powders showed that both the native LTR as well as the modified powders were non-crystalline (Figures 7-10). The clusters of short peaks in the x-ray diffractions are an indication that both the native and the modified powders are natural with multiple constituents.

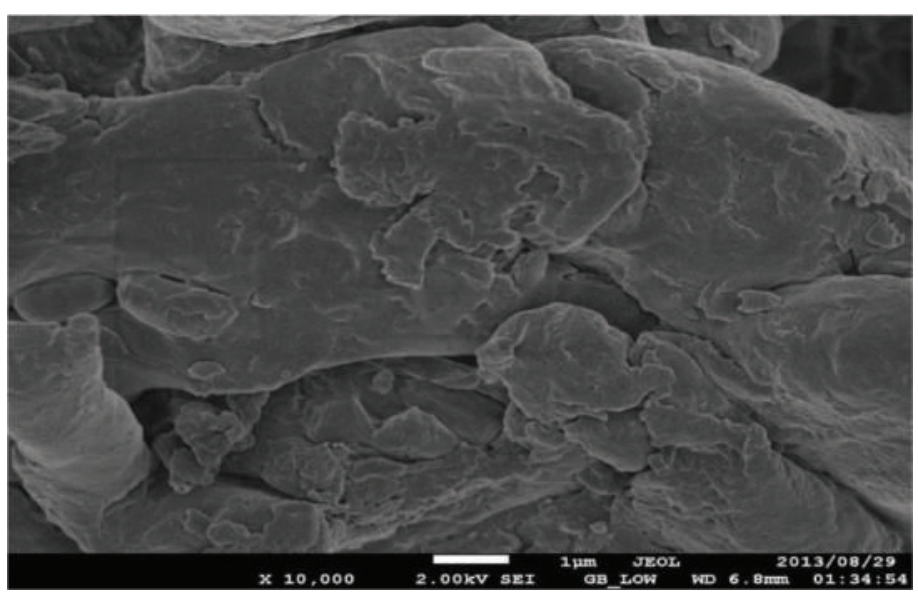

Figure 3. SEM of NLTR-A powder (x 10, 000).

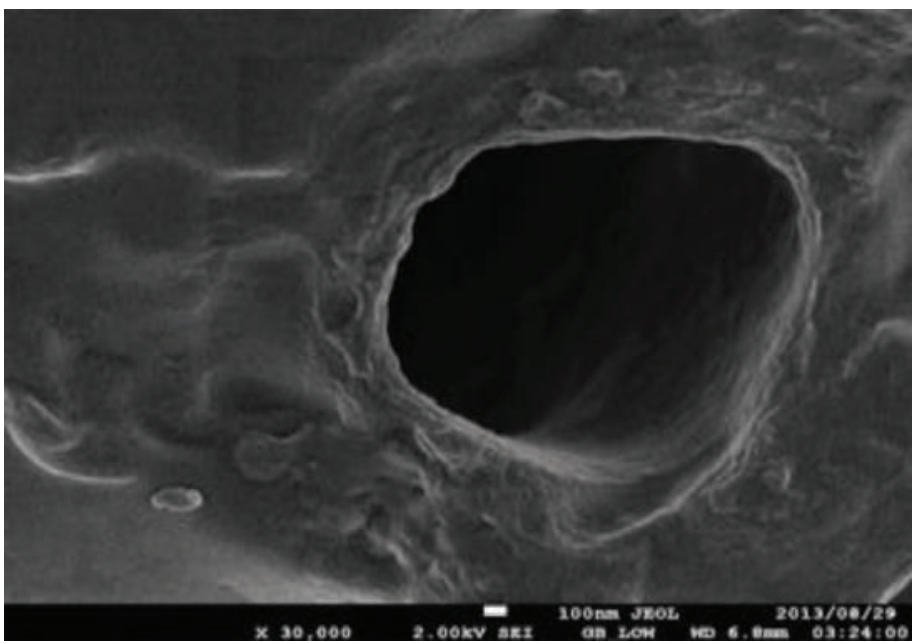

Figure 4. SEM of MLTR-B (x30, 000)

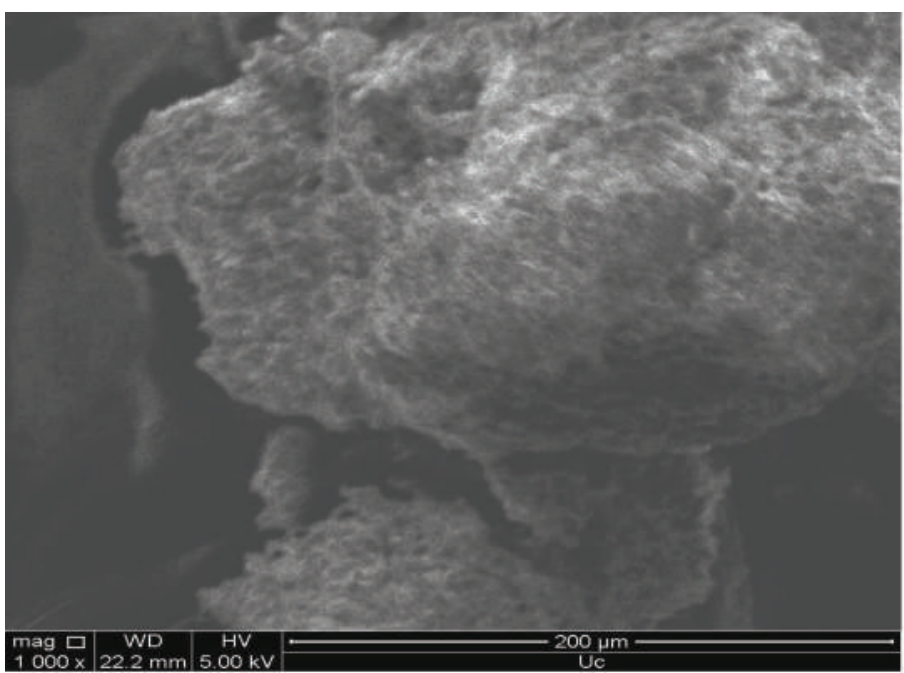

Figure 5. SEM of MLTR-C (x1000) 


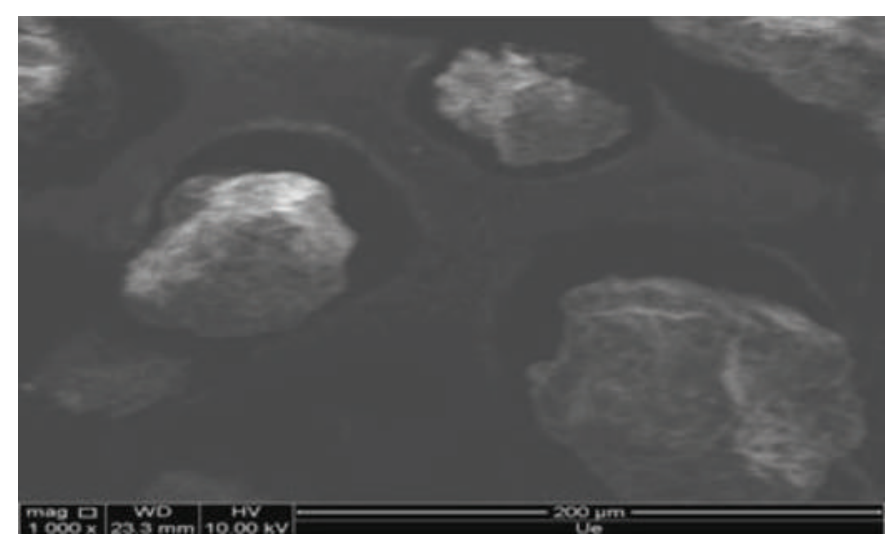

Figure 6. SEM of MLTR-D (x1000)

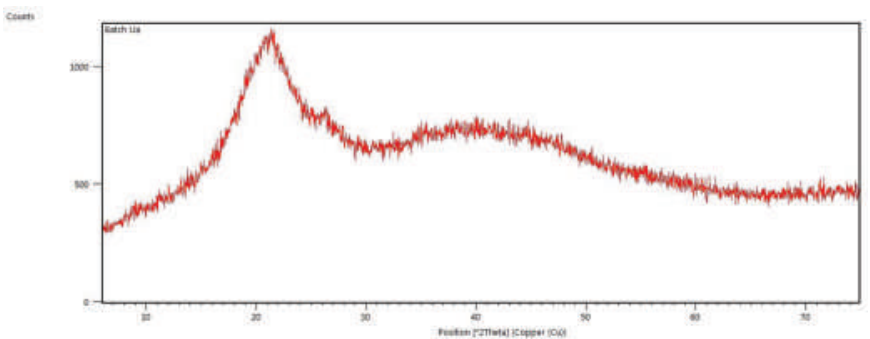

Figure 7. XRD of NLTR-A

\subsection{Flow properties}

Considering the flow properties of the powders, the results gotten revealed that the NLTR-A was not flowable whereas a consistent increase in flow rate was practical in all the modified samples $(\mathrm{p}<0.05)$. Looking at other flow parameters such as the angle of repose, the value got for the NLTR-A was above $50^{\circ}$, a proof of its poor flow properties. On the other hand, a very substantial decrease in the values of angle of repose $\left(<30.0^{\circ}\right)$ were noted for each batch of the modified powders, showing an enhanced flow properties. The improvement in the flow characteristics of the derived powders are further observable from their values of Carr's index and Hausner's ratio. The flowability of powder could be established from the particle packing or storing, where particles in free-flowing solid material generally form a close association upon pouring resulting in a powder bed of low porosity. The values of porosity for the LTR powders decreased steadily from the NLTR-A through all the batches of the modified powders with MLTR-D having the lowest value. Literature shows that particle size, shape and surface texture to a pronounced extent control powder flowability. The existence of moisture in the powder or granule bed may also build up the inter-particle cohesion and thereby cause a decline in flowability $[10,14,27,28$, $13,22]$.

\subsection{Powder densities}

There were consistent increase in values across the modified LTR powders in comparison with the NLTR-A for bulk, tapped and particle densities respectively. A statistically significant variation was noted between the respective bulk and tapped densities of the native and all the modified powders. Powders with insufficient flow properties exhibit larger interparticulate interfaces with more difference between the bulk and tapped densities [29]. This was the case with the NLTR-A which was not flowable. Though, the results obtained for the comparison of the bulk and tapped densities for the modified batches of LTR did not completely fall in line with this literature. A consistent increase in flow parameters at any point of comparison of the modified and the native powders showed a significant difference $(\mathrm{p}<0.05)$ except between MLTR-B and MLTR-C ( $>0.05)$. Particle size increase, through granulation, co-processing or particle engineering is frequently used to minimize the influence of the cohesive forces, and hence boost the flowability of powders [30]. The results obtained revealed that the various methods adopted in the modification of the NLTR-A brought about a great improvement in the hydrophilic and flow characteristics of the MLTR-B, MLTR-C and MLTR-D with MLTR-D exhibiting the best result.

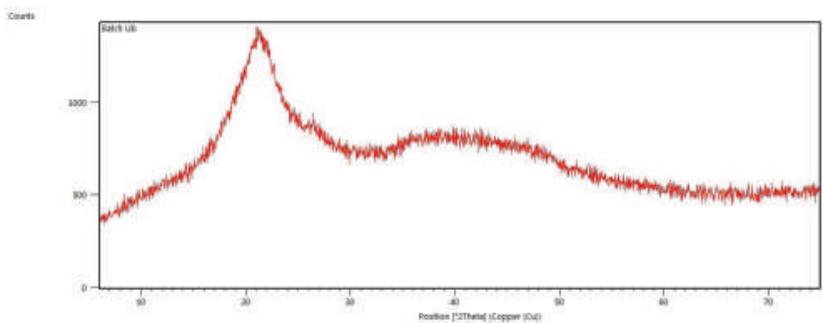

Figure 8. XRD of MLTR-B

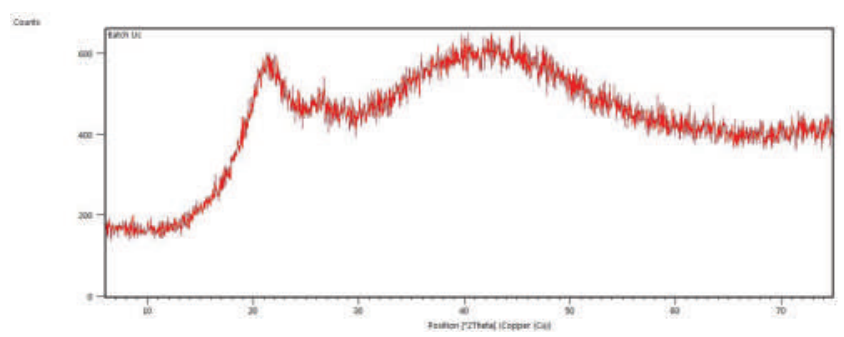

Figure 9. XRD of MLTR-C

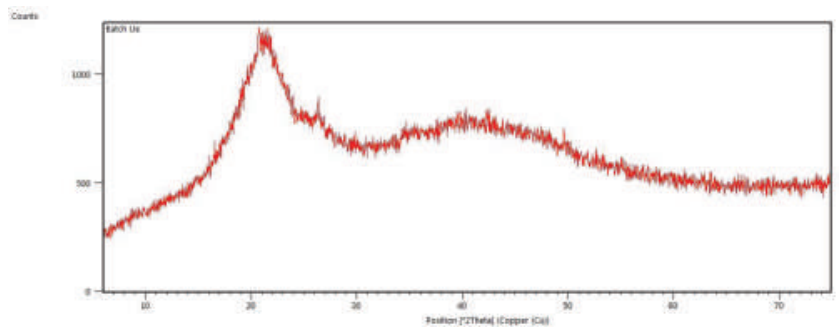

Figure 10. XRD of MLTR-D 


\section{Conclusion}

An attempt was made to modify the native form of Lentinus tuber regium powder. The results obtained showed that the methods used resulted in the enhancement of the hydrophilic and flow properties of the native powder.

\section{References}

[1] Afieroho, O. E., and Ugoeze, K. C. (2014). Gas Chromatography-Mass Spectroscopic (GC-MS) Analysis of n-Hexane Extract of Lentinus Tuber Regium (Fr) Fr (Polyporaceae) Syn Pleurotus tuber regium Fr sclerotia. Tropical Journal of Pharmaceutical research, 13(11), 1911-1915.

https://doi.org/10.4314/tjpr.v13i11.20

[2] Afieroho, O. E., Lawson, L, Adedokun, O. M., and Emenyonu, N. (2013). Antituberculosis and phytochemical investigation of the dichloromethane extract Pleurotus tuber-regium (fries) Singer sclerotium. Int. Res. J. Pharm. 4, 255-7.

[3] Aletor, V. A. (1995). Compositional studies on edible tropical species of mushroom. Food Chem.; 54, 256-268. https://doi.org/10.1016/0308-8146(95)00044-J

[4] Alison, H. (2011). Pharmaceutical excipients - where do we begin? Australian Prescriber, 34(4), 112-114. https://doi.org/10.18773/austprescr.2011.060

[5] Anderson, J. B., and Stasovski, E. (1992). Molecular phytogeny of Northern hemisphere species of Armillaria, Mycologia, 84, 505-516. https://doi.org/10.1080/00275514.1992.12026170

[6] Anike, F. N., Isikhuemhen, O. S., Blum, D. and Neda H. (2015). Nutrient Requirements and Fermentation Conditions for Mycelia and Crude Exo-Polysaccharides Production by Lentinus squarrosulus. Advances in Bioscience and Biotechnology, 6, 526-536. https://doi.org/10.4236/abb.2015.68055

[7] Ansel, H. C., Allen, L. V. and Popovich, N. G. (2005). Pharmaceutical Dosage Forms \& Drug Delivery Systems, 8th ed; Lippincott Williams \& Wilkins; 121-145.

[8] Aulton, M. E. (2002). Pharmaceutics - The Science of Dosage Form Design, 2nd Ed; Churchill Livingstone; 113-138.

[9] Bowen, F. E. and Vadino, W. A. (1984). A simple method for differentiating sources. Drug Dev. Ind. Pharm. 10, 505-511. https://doi.org/10.3109/03639048409041403

[10] Carr, R. L. (1964). Evaluating flow properties of solids, Chemical Engineering, 72, 69-72.
[11] Carstensen, J. T., and Chan, F. C., (1977). Flow rates and a repose angle of wet-processed granulations. J. Pharm. Sci., 66, 1235. https://doi.org/10.1002/jps.2600660907

[12] Chen, T., Wong, K. H., Wu, H., Zheng, W., Wong, M. K., and Man, W. Y. (2013). Pleurotus tuberregium Polysaccharide Functionalized Nano-Selenium Hydrosol with Anti-Tumor Activity and Preparation Method Thereof. United States Patent No: US9072669 B2. 1-16.

[13] European Pharmacopoeia 7th Edition (2013). Monograph 2.9.36. Powder flow. Directorate for the Quality of Medicines of the Council of Europe, Strasbourg.

[14] Hausner, H (1967). Friction conditions in a mass of metal powder. International Journal of Powder Metallurgy, 3, 7-13.

[15] Ikewuchi, C. C., and Ikewuchi, J. C. (2008). Chemical profile of Pleurotus tuber regium (Fr) Sing's sclerotia. Pacific J Sci. Technol. 10, 295-9.

[16] Iwuagwu, M. A., and Onyekweli, A. O., (2002). Preliminary investigation into the use of Pleurotus tuber-regium powder as a tablet disintegrant. Tropical Journal of Pharmaceutical Research, 1(1), 29-37. https://doi.org/10.4314/tjpr.v1i1.14596

[17] Jonathan, S. G., and Akinfemi, A. (2011). Chemical compositions of Zea mays cobs biodegraded by Lentinus subnudus and Pleurotus tuber-regium, BTAIJ, 5(1), 60-65.

[18] Jones, T. M., and Pilpel, N. (1966). The flow properties of granular magnesia. J. Pharm. Pharmacol, 18, 81-93.

https://doi.org/10.1111/j.2042-7158.1966.tb07829.x

[19] Kornblum, S. S., and Stoopak, S. B., (1973). A New Tablet Disintegrant Agent Cross-Linked Polyvinylpyrrolidone, J. Pharm. Sci. 62(1), 43-49. https://doi.org/10.1002/jps.2600620107

[20] Manjunathan, J. and Kaviyarasan, V. (2011). Physicochemical Studies on Lentinus Tuber-regium (FR), A Indian Edible Fungus. International Journal of Pharmacy and Pharmaceutical Sciences, 3(2), 60-63.

[21] Michael, J., Tobyn G. P., McCarthy, I, John N and Staniforth, S. E. (1998). Physicochemical comparison between microcrystalline cellulose and silicified microcrystalline cellulose. Int. J. Pharm. 169, 183-194.

https://doi.org/10.1016/S0378-5173(98)00127-6

[22] Nedderman, R. M., Tüzün, U., Savage, S. B., and Houlsby, G. T. (1982). The flow of granular materials-I: 
Discharge rates from hoppers, Chemical Engineering Science, 37, 1597-1609. https://doi.org/10.1016/0009-2509(82)80029-8

[23] Odeku, O. A., Awe, O. O., Popoola, B, Odeniyi, M. A., and Itiola, O. A. (2005). Compression and mechanical properties of tablet formulations containing corn, sweet potato and cocoyam starches as binders. Pharm. Technol., 29(4), 82-90.

[24] Okhamafe, A. O., and Azubuike, C. P. (1994). Direct Compression of low-cost cellulose derived from maize cob. J. Pharm Sci. Pharmacy Pract. 1, 26-9.

[25] Okoye, E.I \& Onyekweli, A.O (2016). Development and evaluation of Pleurotus tuber-regium-cornstarch composite as a direct compression multifunctional excipient, Int. J Pharm Invest. 6(1): 10-22. https://doi. org/10.4103/2230-973X.176461

[26] Oso, B. A. (1977). Pleurotus tuber-regium from Nigeria. Mycolagia, 69, 271-279. https://doi.org/10.1080/00275514.1977.12020058

[27] Schulze, D. (2008). Powders and Bulk Solids; Behavior, Characterization, Storage and Flow. New York: Springer Berlin Heidelberg.

[28] Schwedes, J. (2003). Review on testers for measuring flow properties of bulk solids (based on an IFPRIReport 1999), Granular Matter, 5, 1-43. https://doi.org/10.1007/s10035-002-0124-4

[29] Shangraw, R. F. Wallace, J. W., and Bowers, F. M. (1987). Morphology and functionality in tablet excipient for direct compression; Pharm. Technol., 11, 136-143.

[30] Summers, M.P., and Aulton, M.E. (2007). Granulation, In: Aulton ME, editor. Aulton's Pharmaceutics: The design and manufacture of medicines, $3 \mathrm{Ed}$, Churchill Livingstone, Edinburgh, 410-424.

[31] The Joint IPEC (2006). PQG Good Manufacturing Practices Guide for Pharmaceutical Excipients.

[32] The Pharmaceutical Codex (1994). Principles and Practice of Pharmaceutics, 12th ed. Walter L; editor. The Pharmaceutical Press, London, p. 696.
[33] Ugoeze, K. C., and Nkoro, V. O. (2015). The PhysicoTechnical Properties of a Multicomponent Lentinus tuber regium Based Co-processed Excipient (Fizlent). American Journal of Pharmacy and Pharmacology. 2(3), 13-20.

[34] Ugoeze, K. C., Nkoro, V. O., and Nwachukwu, N. (2015). Application of a Multicomponent Lentinus tuber regium Based Co-Processed Excipient (Fizlent) as a Novel Directly-Compressible Filler-BinderSuperdisintegrant in Ibuprofen Tablet Formulation. American Journal of Biomedical Science and Engineering. 1(4), 45-50.

[35] Ugoeze, K. C., and Okpara, C. (2015). Characterization of a novel coprocessed powder of Lentinus tuber regium and polyvinylpyrollidone (Povilent). International Research Journal of Pharmaceutical and Applied Sciences 5(2), 15-21.

[36] Ugoeze, K. C., Nwaokenye, C. and Ibezim, C. N. E. (2013). Studies on the disintegrant and drug release rate enhancing properties of admixtures of corn starch BP and Lentinus tuber - regium powders in wet granulated paracetamol tablet. African Journal of Pharmaceutical Research and Development 5(2), 83-90.

[37] Zeleznik, J. A., and Renak, J. L. (2001). Flow and compact properties of dibasic calcium phosphate blended with microcrystalline cellulose and silicified microcrystalline cellulose: a paper presented at the American Association of Pharmaceutical Scientists Annual Meeting and Exposition, Denver, Colorado.

[38] Zhang, M., Zhang, L., Cheung, P. C. and Ooi, V. E. (2004). Molecular weight and anti-tumor activity of the water-soluble polysaccharides isolated by hot water and ultrasonic treatment from the sclerotia and mycelia of Pleurotus tuber-regium. Carbohydr Polym. 56, 123-8.

https://doi.org/10.1016/j.carbpol.2004.01.005 